\title{
Public Service Broadcasting and the Public Sphere: Normative Arguments from Habermasian Theory
}

PHIL RAMSEY, University of Ulster

\section{ABSTRACT}

Discussing Public Service Broadcasting from the perspective of the public sphere has both historical form and theoretical rationale. This article surveys some of the arguments forwarded on the commonality between the theoretical category of the public sphere, and Public Service Broadcasting (PSB). Drawing from scholarly work over the past three decades, it also addresses the problems with this approach, outlining an argument against applying public sphere theory in this setting. This article then applies normative arguments drawn from Habermasian theory to the subject, arguing that public sphere theory remains a critical tool for studying PSB. This article suggests that on the public sphere principles of inclusion, deliberation and opinion formation, PSB helps sustain the notion of the public sphere, and indeed provides one of the most important realisations of it. In particular, this article focuses on PSB in the UK, and gives evidence from the case of the BBC to support its claims.

\section{KEY WORDS}

Public Service Broadcasting, Public Sphere Theory, Jürgen Habermas, BBC 
This article will address Public Service Broadcasting from the perspective of public sphere theory. Having addressed the range of arguments forwarded on the commonality between the theoretical category of the public sphere, and of Public Service Broadcasting (PSB), I will forward three normative arguments for PSB as an underpinning and enabling force of the public sphere. Addressing PSB in the UK, this article will address the principle of inclusion, the principle of deliberation, and the principle of opinion formation. In particular, I will adopt Jürgen Habermas's theory of the public sphere, mainly set out in The Structural Transformation of the Public Sphere (1989) (STPS), but will also draw on his other and sometimes differing accounts (1997; 2006; 2009). Given the scope of this article, I will not have the space to consider the many competing theories of the public sphere, that are critical of Habermas's account. This article will thus not consider the full range of arguments that could be made on this subject, but rather serves as an overview of the central points, and may act as a stimulus for further scholarly debate.

\section{PSB and public sphere theory: an overview}

Contemporary academic discourse has drawn comparisons between the public sphere and PSB. Theorists have debated whether or not PSB is formative of the public sphere and crucial to its existence. Curran (1991), Garnham (1986) and Scannell (1989) argue that PSB fits the central Habermasian public sphere narrative. Curran argues that Habermas's account of the public sphere was historically flawed (1991: 42), but British PSB offers a clearer example of Habermas's normative conception of the public sphere. On this he argues:

His conception of reasoned discourse is closer to the practice of British public-service broadcasting, with its ideology of disinterested professionalism, its careful balancing of opposed points of view and umpired studio discussions that it is to that of the polemicist and faction-ridden London press of the eighteenth century, operating in the context of secret service subsidies, opposition grants and the widespread bribing of journalists. (ibid.)

Curran is suggesting that the normative element of Habermas's work closely mirrors that of the operation of the BBC. He argues that conceiving of a model of multiple and competing public spheres better fits Habermas's time period of analysis, and that rather it is not until the PSB era and 
the $\mathrm{BBC}$, but before satellite television, that we can point to a "unitary public sphere" (ibid.: 43).

In a similar way, Garnham argues that addressing the model of PSB as an analogy of the public sphere is important, given that the two models share the same "strengths and weaknesses" (1986: 45). For Garnham the strength of PSB, based upon the imperatives of public sphere theory is that "it (a) presupposes and then tries to develop in its practice a set of social relations which are distinctly political rather than economic, and (b) at the same time attempts to insulate itself from control by the state as opposed to, and this is often forgotten, political control" (ibid.). Despite his arguments in support of the PSB model, Garnham notes, "its failure to recognize the problem of mediation within the Public Sphere and thus the role of knowledge-brokers within the system" (ibid.: 49). Here he is particularly thinking about the "social function of both journalists and politicians" (Garnham, 1986: 49). In relation to journalists, he argues that they are largely unaccountable on the measure of how they serve the public interest, and lack adequate training.

Scannell argues for the foundational role of public sphere theory in "the study of modern societies and the contributory role of modern media" (Scannell, 1989: 136). Arguing that PSB must be first and foremost "a service to the public" (ibid.: 135), Scannell asserts that PSB is crucial to the very idea of publicness:

What was public life before broadcasting? In a general sense there were certain kinds of buildings and spaces in which people could meet, outside their homes, for relaxation, pleasure or selfimprovement; public parks and libraries and public houses. More specifically there were public events that took place in particular places for particular publics. (ibid.: 139-140)

In one sense, he is at odds here with Habermas, in that PSB does not feature much in Habermas's central account in STPS (although I will address how it appears in his later work). However, as many scholars argue, the Habermasian model of the public sphere retains a normative value that renders it necessary and critical (Castells, 2008; Curran, 2000; Durham-Peters, 1993; Garnham, $1986 ; 1992 ; 2007)$. It is to this normative value that Scannell attaches his argument about publicness; for him, it is under PSB that the public sphere is finally realisable. Whilst Habermas argues, "Access to the public sphere is open in principle to all citizens" (1997: 105), for Scannell this did not happen during Habermas's time period. Rather, it is PSB that enables this inclusive condition. On this he argues, "The fundamentally democratic thrust of broadcasting lay in the new 
kind of access to virtually the whole spectrum of public life that radio first, and later television, made available to all” (Scannell, 1989: 140).

The central critique of applying public sphere theory to PSB comes from Keane (1995), who dismisses the idea that the public sphere and PSB can be used as analogous categories (Keane, 1995: 4). Setting aside his concerns - amongst which are that Garnham over looks the problems of drawing a line between the historical conditions of the public sphere "with the peculiarly twentiethcentury practice of electronic broadcasting" (ibid.) - Keane suggests that there has been great decline in the public service model throughout the twentieth century. This is similar to the argument made by Golding that "the translation and dissemination of Habermas's ideas in English, has coincided with the crisis in public service broadcasting, and indeed the public sphere more generally" (1995: 26).

To understand this decline, Keane identifies three causes:

(1) "Fiscal squeeze": by this he means that public service broadcasters have faced deteriorating incomes, as rising incomes peaked in the 1970s (Keane, 1995.: 5)

(2) "Legitimacy problems": by this he means that "both audiences and broadcasters sense that the public service claim to representativeness is in fact a defence of virtual representation of a fictive whole, a resort to programming which simulates the actual opinions and tastes of some of those at whom it is directed" (ibid.: 6). As an example here he offers the example of the problems of trying to reflect a national music culture in PSB, given the myriad "publics" with different tastes in music.

(3) "Technological change": by this he means that new and emerging technologies (writing in 1995) have "destroyed the traditional argument that the scarcity of available spectrum blesses public service broadcasting with the status of a 'natural monopoly' within the boundaries of a given nation state" (ibid.: 7).

Broadly, as a result of these three points, Keane rejects the comparison between the public sphere and PSB, given the fundamental shift in the environment in which public service broadcasters operate. Instead he argues, we should bring the concept to bear on "phenomena as disparate as 
computer networking, citizen's initiatives, newspaper circulation, satellite broadcasting, and children playing video games" (ibid.: 16).

If the account from Curran, Garnham, Scannell and Keane represent the two main sides of the debate, Karppinen et al. (2008) argue for a more nuanced understanding of the common ground between public sphere theory and PSB. On one hand they suggest that "Practices of public service broadcasting have historically never corresponded to the ideal public sphere. Nor do they automatically fit a future realisation or approximation" (2008: 12). However, on the other hand they argue "public service broadcasting can be presented as the institutional space which is best able to realise the principles of communicative action in the public sphere: freedom from commercial pressures, undistorted communication, consensual procedures, rational debate and at least ideally the expression of social unity" (ibid.: 13). In pursuing a way forward, Karppinen et al. suggest that the Habermasian account should be held in tension with Chantal Mouffe's account of agonistic pluralism. In Mouffe's account, she sets out to critique deliberative democracy - a category closely associated with debate on the public sphere - suggesting that the basic premise underpinning deliberative democracy is wrongly conceived (1999). She argues that democratic legitimacy should come not come through rationality, as democracy should never try to eliminate antagonisms between different groups.

This debate connects back to PSB with regard to the manner in which PSB deals with difference and diversity within society, and how public service broadcasters portray this in the type of content that they produce. On this Karppinen et al. argue that the arguments for PSB can be made from the model of agonistic pluralism:

In a political and cultural environment which has promoted difference and pluralism, arguments for public service broadcasting need to consider more fully the issues of pluralism and conflict. Such an understanding of the democratic role of the media informed by an agonistic model of democracy provides an alternative to both the singular proliferation of private media outlets and the outmoded view of public broadcasting. (Karppinen et al., 2008: 13)

As they advance their argument, they eventually accept that there is value from the accounts of both Habermas and Mouffe (ibid.: 14). It is however to the central Habermasian account of the public 
sphere that I turn to, to make normative arguments for the role and position of PSB in constituting the public sphere. In part, I want to draw on later Habermasian theory, when Habermas turns directly to the subject of PSB, in a manner that he had hitherto left unexplored to any great extent. Here I want to turn to three core public sphere principles, and to show how PSB fulfills these principles, in a manner that is seen less elsewhere in the "media system" (Habermas, 2009: 166). In particular, I am referring to PSB conditions in the UK, as realised through the TV Licence that funds the BBC.

\section{The Principle of Inclusion}

The principle of inclusion can be seen throughout Habermas's public sphere account: "Access to the public sphere is open in principle to all citizens" (Habermas, 1997: 105). Whilst this was not the case in the historic setting as Habermas initially wanted to suggest, as a principle it remains important kernel to the idea of a public sphere: PSB is in principle open to all, as well as being fairly successful at achieving inclusiveness. On this we can point to a number of factors to find corroboration for this. First, the cost of purchasing a TV licence is comparatively low, compared to UK average income and compared to other media subscription services. The monthly cost of the licence fee equates to $£ 12.13$, or roughly $£ 4$ per week (Ramsey, 2010a: 13). In contrast, the median "weekly pay for full-time employees in the UK grew by 2.0 per cent in the year to April 2009 to reach $£ 489$ ” (ONS, 2009). Whilst this does not take account of people on benefits, some pensioners, and those who earn much less than the median amount, it still represents a fairly low and affordable cost for most of the population. Outside of this, the TV licence is free for those seventy-five years of age and over, discounted by half for the blind, and costs a statutory amount of $£ 5$ for those living in residential care (Directgov, 2010). Compared to the BBC's main competitor, BSkyB, the cost of the TV Licence is remarkably low. In June 2010, the cheapest package advertised by BSkyB in June 2010 was $£ 18 /$ month (BSkyB, 2010). As I have shown elsewhere, "Whilst this price includes free phone and broadband provision, it must be noted that to receive additional content to that which is commonly free-to-air with FreeView or FreeSat, costs much more" (Ramsey, 2010a: 14). However, for a Sky package that includes elements that are distinctive to the service, including entertainment, movies and sport, costs $£ 48.50 /$ month (BSkyB, 2010). 
Second, equipment costs to engage with PSB in the UK remain low and would not be considered prohibitive to accessibility. Whilst purchasing a television may remain relatively expensive (though cheaper in 2010 than ever before), one can access scores of BBC radio stations and access hundreds of hours of public service programming, from a radio that can be purchased for a couple of pounds. Moreover, as the Coalition Government pursues a policy of "digital switch over", allowance has been made for providing assistance for those who need help with changes to equipment (BBC, 2010a). Third, PSB remains considerably more financially accessible than the Internet, which remains inaccessible to many in the UK, with 30 per cent of people without personal online access (ibid.). This group breaks down roughly into two groups: those excluded for financial reasons, and those excluded through lack of interest. On the first, fifty-five percent of people excluded for financial reasons live in "social category DE homes" (DCMS, 2009: 33. As I have argued elsewhere, "That the disadvantaged socioeconomically are more likely to be digitally excluded, should be of no surprise, given that the cost of accessing the Internet remains relatively high and prohibitive to many" (Ramsey, 2010b: 1). The cost of having Internet access at home, which includes expensive equipment and relatively high monthly charges, may run to many hundreds of pounds. On the second, an Ofcom report "found that even if a computer and Internet connection were provided for free to those without the Internet at home, 43 per cent would decline this offer" (ibid.). Moreover, we see problems in terms of broadband provision to certain remote parts of the country to a much greater extent than that of lack of access to television and radio signals. On these counts, financial exclusion, lack of interest, and lack of coverage we see nothing comparable to PSB. Rather PSB remains relatively affordable to the user in terms of the TV Licence and equipment, uptake and access of PSB is almost universal.

\section{The principle of deliberation}

The principle of deliberation is at the centre of the public sphere, and has led to much shared scholarly work between public sphere theory and deliberative democracy theory. As citizens debate and deliberate on ideas, the public sphere is formed and reformed. Habermas argues in STPS that "a set of basic rights concerned the sphere of the public engaged in rational-critical debate (freedom of opinion and speech, freedom of press, freedom of assembly and association etc.) and the political function of private people in this public sphere (right of petition, equality of vote etc.)" (1989: 83). 
In order to debate in an informed manner, interlocuters in the public sphere must have access to information of a political nature. Whilst this is by no means limited to PSB, it is perhaps public service broadcasters who provide the most accessible and voluminous content of a serious political nature. This information can then be tested, proved and analysed in the public sphere, in debate that takes place in the public square, the workplace and the coffee house (as in Habermas's historical account). Public service content provides the material needed for interlocutors to participate in what Habermas calls "rational-critical" debate (ibid.: 58).

How this debate takes place, and indeed the societal structures that the public sphere requires for debate to take place, is itself another subject. A public well informed by PSB, but without the means to debate the information, is a poor reflection of Habermas's public sphere. In his later work (2006; 2009), Habermas accepts the dominance of the media system over face-to-face debate, although he does argue that that this leads to a poorer quality public sphere. On this he argues that the political public sphere that does remain, is "dominated by the kind of mediated communication that lacks the defining features of deliberation", with a shortfall in "face-to-face interaction between present participants in a shared practice of collective decision-making" and a "lack of reciprocity between the roles of speakers and addressees in an egalitarian exchange of claims and opinions" (2006: 8-9). Habermas is unequivocal about the importance of the role that he thinks Public Service Broadcasting plays. He states: "Its loss would rob us of the centerpiece of deliberative politics" (ibid.: 27). In other words, if PSB was eventually completely eroded, the very centre of the public sphere would be lost.

The 'refeudalised' public sphere - the term that Habermas uses in STPS to chart the shift from the bourgeois public sphere to the one we can chart contemporaneously- is a poor reflection of the normative public sphere model that I deploy. Increasingly, the public do not have the institutional infrastructure required to participate in an 'ideal-type' public sphere. Indeed, it is here that PSB may play a role: not only supplying the content necessary for a functioning public sphere, but the infrastructure for it also. This has been the case for many years, whereby television and radio phone-ins provide one of the few ways of sustaining a national debate. They remain one of the few ways that a member of the public in the Shetland Islands may get a sense of the general opinion on an issue from the Channel Islands. The Internet, and its use by public service broadcasters, provides potential for greater deliberation here also. Dahlberg (2001) argues that the Internet is not an ideal 
provider of deliberative democratic ideals, and is rather colonised by state and corporate interests (much like Habermas's refeudalised public sphere). However, he reasons that "online spaces free from state and corporate power must be put aside for public deliberation; financial support from government and non-government sources is desperately needed to develop these spaces" (2001: 629). Here he leans on Blumler and Gurevitch's argument in The New Media and our Political Communication Discontents (2001), where they proposed "the creation of a publicly funded authority, independent of government, that would have the responsibility of encouraging, coordinating, publicizing, and resourcing online deliberative initiatives" (ibid.: 630). In this article, Blumler and Gurevitch use the analogy of the history of radio; in this period the USA largely went with a market model, whilst European states largely favoured public service provision. For them, "The corresponding challenge today is to fashion and apply a public service remit for the Internet and other online service"' (2001: 9). However, the use of the Internet by public service broadcasters holds potential here too. Already, in the UK the BBC enables its audience online to comment on news stories, through the "Have Your Say" service (BBC, 2010b). Further developments might and should occur, enabling PSB to further underpin the public sphere in terms of the principle of deliberation.

\section{The principle of opinion formation}

The principle of opinion formation is one that is central to the public sphere, Habermas states: "By 'public sphere' we mean first of all a domain of our social life in which such a thing as public opinion can be formed" (1997: 105). Interlocutors within the public sphere carry out reasoned and rational debate, and from this have the ability to form critical opinions on matters of public importance. Through exposure to ideas, members of the public formulate opinions, which taken collectively formulate public opinion. On this principle, PSB provides a crucial means to enabling this. In the UK, the BBC is required institutionally and structurally to commit to a certain amount of 'public service' content. By this I mean that the BBC broadcasts a very large amount of programming on news and current affairs, as well as on areas such as religion (an area not readily served by market provision and are required to cover a range of subjects, to give air-time to many cultural and political groups, and to report in a balanced and fair manner. Despite numerous charges of 'dumbing-down', and of the 'celebrification' of content (some of which are warranted) the BBC 
remains at the forefront of PSB on a global scale.

In his later work, Habermas (2009) holds that the quality press must remain at the centre of the public sphere, but as my argument relates to broadcasting, it is that area that I will focus on. In terms of broadcasting in a "refeudalised" public sphere, commercial and market-driven broadcasters are less effective at providing the necessary infrastructure for a functioning public sphere. On this point, Habermas is unequivocal:

Under the pressure of shareholders who thirst for higher revenues, it is the intrusion of the functional imperatives of the market economy into the 'internal logic' of the production and presentation of messages that leads to the covert displacement of one category of communication by another: [...] Besides personalization, the dramatization of events, the simplification of complex matters, and the vivid polarization of conflicts promotes civic privatism and a mood of anti-politics. (Habermas, 2006: 26-27)

Thus he argues, greater marketisation of media lead us away from 'public communication', and in particular the type of journalism that PSB is required by statute in the UK to deliver. Instead, we are left with commercialised media delivering content that we recognise from Habermas's description especially the point about broadcasters "simplifying complex matters". The normative argument here that can be derived from public sphere theory is that PSB must remain at the centre of the public sphere. However, in the UK the drift is towards putting PSB under greater threat; these threats come from competitors (see James Murdoch's 2009 MacTaggart Lecture - discussed in Ramsey, 2010a), from government (see freeze in the TV licence until 2016-2017 announced in the Spending Review (HM Treasury, 2010: 66), and from within the BBC itself. Here, it is particularly worthwhile to note that the BBC strategy document Putting Quality First (BBC, 2010c), argues against some of the fundamental principles of PSB on a footing that is contrary to the evidence contained within the document itself.

In conclusion, the theory of the public sphere as forwarded by Habermas remains a cogent and critical theory to apply to PSB, and is useful for making arguments in its favour. In particular, the theory of the public sphere remains flexible enough to change with developments in media and culture. However, it also remains rigid enough to deploy when making normative arguments, and 
allows the public sphere researcher to make concrete claims as to how society ought to be structured. In this article, I have not had the space to set out the problems with the PSB model generally, and with the $\mathrm{BBC}$ as it exists today more specifically. These problems are not insignificant, especially on the subject of increasing levels of content that are not distinctively 'public service' in their nature. Whilst I have argued that the BBC remains a good provider of serious political content, necessary for deliberation and opinion formation, it has also been complicit in a more general slide towards replacing news with 'infotainment'. Indeed, in returning to Habermas's point shown above - "the simplification of complex matters, and the vivid polarization of conflicts" (Habermas, 2006: 26-27) - we can recognise this in much BBC content. However, PSB on the whole remains one of the most satisfactory ways of sustaining a functioning public sphere, whilst the theory of the public sphere remains an important theoretical narrative for making arguments on behalf of PSB. 
Networking Knowledge: Journal of the MeCCSA Postgraduate Network, Vol. 3, No. 2 (2010)

\section{References}

BSkyB (2010) 'Packages', Available from: http://www.sky.com/quickbuy/build [accessed: 01/06/10].

BBC (2010a) 'Switchover Help Scheme', Available from: http://www.helpscheme.co.uk/ [accessed 15.10.10].

BBC (2010b) 'Have Your Say', Available from: http://www.bbc.co.uk/news/have_your_say/ [accessed 15.10.10].

BBC (2010c) Putting Quality First: The BBC and Public Space. London: BBC Trust.

Blumler, J.G. \& Gurevitch, M. (2001) 'The New Media and our Political Communication Discontents', Information, Communication \& Society, Vol.4(1): 1 - 13.

Castells, M. (2008) 'The New Public Sphere: Global Civil Society, Communication Networks, and Global Governance', The ANNALS of the American Academy of Political and Social Science, 616, $1,44-61$.

Curran, J. (1991) 'Rethinking the Media as a Public Sphere’ In: Dahlgreen, P. \& Sparks, C. (eds.) Communication and Citizenship: Journalism and the Public Sphere in the New Media Age, London: Routledge, pp. 27-57.

Curran, J. (2000) 'Rethinking Media and Democracy' In: Curran, J. \& Gurevitch, M. (eds.) Mass Media and Society, London: Arnold, pp.120-154.

Dahlberg, L. (2001) 'The Internet and Democratic Discourse: Exploring the prospects of online deliberative forums extending the public sphere', Information, Communication \& Society, Vol. 4(4): $615-633$.

DCMS (2009) Digital Britain, London: HMSO. 
Networking Knowledge: Journal of the MeCCSA Postgraduate Network, Vol. 3, No. 2 (2010)

Directgov (2010) 'Free TV licences', Available from: http://www.direct.gov.uk/en/Pensionsandretirementplanning/Benefits/ConcessionsAndOtherHelp/D G 10018651 [accessed 15.10.10].

Durham-Peters, J. (1993) 'Distrust of representation: Habermas on the public sphere', Media Culture Society, Vol.15: 541-571.

Garnham, N. (1986) 'Media and the public sphere' In: Golding, P., Murdock, G. \& Schlesinger, P. (eds.) Communicating Politics, Leicester: Leicester University Press, pp.37-53.

Garnham, N. (1992) 'The Media and the Public Sphere' In: Calhoun, C. (ed.), Habermas and the Public Sphere, London: MIT Press, pp. 359-376.

Garnham, N. (2007) 'Habermas and the Public Sphere', Global Media \& Communications, Vol.3(2): 201-214.

Golding, P. (1995) 'The Mass Media and the public sphere: The Crisis of information in the "information society" in Edgell, S. et. al (eds.) Debating the Future of the Public Sphere, Aldershot: Avebury., pp.25-40.

Habermas, J. (1989) Structural Transformation of the Public Sphere. Cambridge: Polity.

Habermas, J. (1997) 'The Public Sphere' In: Goodin, R. \& Pettit, P. (eds.) Contemporary Political Philosophy, Oxford: Blackwell, 103-106.

Habermas, J. (2006) 'Political Communication in Media Society - Does Democracy still enjoy an epistemic dimension? The impact of normative theory on empirical research', paper presented at the ICA Annual Convention Dresden, June, 2006, Available from: http://www.icahdq.org/Speech_by_Habermas.pdf [accessed 20.10.08].

Habermas, J. (2009) Europe: The Faltering Project. Cambridge: Polity. 
Networking Knowledge: Journal of the MeCCSA Postgraduate Network, Vol. 3, No. 2 (2010)

HM Treasury (2010) CM 7942: Spending Review 2010. London: HMSO.

Karppinen et al. (2008) 'Habermas, Mouffe and Political Communication: A Case For Theoretical Eclecticism', Javnost-The Public, Vol.15(3): 5 - 22.

Keane, J. (1995) 'Structural transformations of the public sphere', Communication Review, Vol.1: $1-22$.

Mouffe, C. (1999) 'Deliberative Democracy or Antagonistic Pluralism?', Social Research, Vol. 66(3): 745-758.

ONS (2009) 'Earnings: 2009 Annual Survey of Hours and Earnings (ASHE)', http://www.statistics.gov.uk/cci/nugget.asp?id=285 [accessed 15.10.10].

Ramsey, P. (2010a) "Response to BBC Strategy Review 2010”, Media Policy Briefing Paper No.6, University of Ulster: Centre for Media Research, ISSN 1748-0175 (Print), http://cmr.ulster.ac.uk/pdf/CMRbriefingpaper-PhilRamsey-BBC.pdf. [accessed 14.10.10].

Ramsey, P. (2010b) "Digital citizenship and inclusion: a social democratic agenda”, Compass Thinkpieces: Thinkpiece \#61,

http://clients.squareeye.com/uploads/compass/documents/CTP65RamseyDigital.pdf. [accessed 14.10.10].

Scannell, P. (1989) 'Public service broadcasting and modern public life', Media, Culture \& Society, Vol.11: (135-166). 